\title{
Conditions during adulthood affect cohort-specific reproductive success in an Arctic-nesting goose population
}

Mitch D Weegman, Stuart Bearhop, Geoff M Hilton, Alyn Walsh, Anthony David Fox

Variation in fitness between individuals in populations may be attributed to differing environmental conditions experienced among birth (or hatch) years (i.e., between cohorts). In this study, we tested whether cohort fitness could also be explained by environmental conditions experienced in years post-hatch, using 736 lifelong resighting histories of Greenland white-fronted geese (Anser albifrons flavirostris) marked in their first winter. Specifically, we tested whether variation in age at first successful reproduction, the size of the first successful brood and the proportion of successful breeders by cohort was explained by environmental conditions experienced on breeding areas in west Greenland during hatch year, those in adulthood prior to successful reproduction and those in the year of successful reproduction, using North Atlantic Oscillation indices as proxies for environmental conditions during these periods. Fifty-nine (8\%) of all marked birds reproduced successfully (i.e., were observed on wintering areas with young) only once in their lifetime and 15 (2\%) reproduced successfully twice or thrice. Variation in age at first successful reproduction was explained by the environmental conditions experienced during adulthood in the years prior to successful reproduction. Birds bred earliest (mean age 4) when environmental conditions were good prior to the year of successful reproduction. Conversely, birds successfully reproduced at older ages (mean age 7 ) if they experienced adverse conditions prior to the year of successful reproduction. Hatch year conditions and an interaction between those experienced prior to and during the year of successful reproduction explained less (marginally significant) variation in age at first successful reproduction. Environmental conditions did not explain variation in the size of the first successful brood or the proportion of successful breeders. These findings show that conditions during adulthood prior to the year of successful reproduction are most important in determining the age at first successful reproduction in Greenland white-fronted geese. Very few birds bred successfully at all (most only once), which suggests that May environmental conditions on breeding areas have cohort effects that influence lifetime (and not just annual) reproductive success. 


\section{Conditions during adulthood affect cohort-specific reproductive}

\section{2 success in an Arctic-nesting goose population}

4 Mitch D. Weegman ${ }^{1,2 *}$, Stuart Bearhop ${ }^{1}$, Geoff M. Hilton ${ }^{2}$, Alyn J.Walsh ${ }^{3}$,

5 Anthony David Fox ${ }^{4}$

6

$7{ }^{1}$ Centre for Ecology and Conservation, College of Life and Environmental Sciences, University

8 of Exeter, Cornwall Campus TR10 9EZ, United Kingdom

${ }^{2}$ Wildfowl \& Wetlands Trust, Slimbridge, Gloucester, GL2 7BT, United Kingdom

${ }^{3}$ National Parks and Wildlife Service, Wexford Wildfowl Reserve, North Slob, Wexford, Ireland

${ }^{4}$ Department of Bioscience, Aarhus University, Kalø, Grenåvej 14, DK-8410 Rønde, Denmark

*Present address: Department of Fisheries, Wildlife \& Conservation Biology, University of Minnesota, St. Paul, MN 55108 USA

Corresponding author:

Mitch D. Weegman ${ }^{1,2 *}$

${ }^{1}$ Centre for Ecology and Conservation, College of Life and Environmental Sciences, University of Exeter, Cornwall Campus TR10 9EZ, United Kingdom

${ }^{2}$ Wildfowl \& Wetlands Trust, Slimbridge, Gloucester, GL2 7BT, United Kingdom

*Present address: Department of Fisheries, Wildlife \& Conservation Biology, University of Minnesota, St. Paul, MN 55108 USA

Email address: weegm009@umn.edu 


\section{Abstract}

32 Variation in fitness between individuals in populations may be attributed to differing environmental conditions experienced among birth (or hatch) years (i.e., between cohorts). In this study, we tested whether cohort fitness could also be explained by environmental conditions experienced in years post-hatch, using 736 lifelong resighting histories of Greenland whitefronted geese (Anser albifrons flavirostris) marked in their first winter. Specifically, we tested whether variation in age at first successful reproduction, the size of the first successful brood and the proportion of successful breeders by cohort was explained by environmental conditions experienced on breeding areas in west Greenland during hatch year, those in adulthood prior to successful reproduction and those in the year of successful reproduction, using North Atlantic Oscillation indices as proxies for environmental conditions during these periods. Fifty-nine (8\%) of all marked birds reproduced successfully (i.e., were observed on wintering areas with young) only once in their lifetime and $15(2 \%)$ reproduced successfully twice or thrice. Variation in age at first successful reproduction was explained by the environmental conditions experienced during adulthood in the years prior to successful reproduction. Birds bred earliest (mean age 4) when environmental conditions were good prior to the year of successful reproduction.

47 Conversely, birds successfully reproduced at older ages (mean age 7) if they experienced adverse conditions prior to the year of successful reproduction. Hatch year conditions and an interaction between those experienced prior to and during the year of successful reproduction explained less

50 (marginally significant) variation in age at first successful reproduction. Environmental conditions did not explain variation in the size of the first successful brood or the proportion of successful breeders. These findings show that conditions during adulthood prior to the year of successful reproduction are most important in determining the age at first successful 
54 reproduction in Greenland white-fronted geese. Very few birds bred successfully at all (most

55 only once), which suggests that May environmental conditions on breeding areas have cohort

56 effects that influence lifetime (and not just annual) reproductive success.

\section{Introduction}

59 Individual variation in fitness is a feature of vertebrate populations (Gaillard et al., 2000), some

60

61

62

of which results from annual variation in conditions experienced during early life (Scether, 1997), giving rise to 'cohort effects' (Lindström, 1999). Cohort effects are well documented in birds (van der Jeugd \& Larsson, 1998; Krüger \& Lindström, 2001; Reid et al., 2003) and mammals (Rose, Clutton-Brock \& Guinness, 1998; Coltman et al., 1999; Descamps et al., 2008), where subsequent fitness has been linked to birth year conditions via life history traits. For example, Soay sheep (Ovis aries) born after warm, wet winters produced more offspring as adults than those born after cold, dry winters (Forchhammer et al., 2001). In some birds, juvenile survival, probability of recruitment into the breeding population and breeding longevity were positively correlated with the quality of a cohort's natal environment (Reid et al., 2003). Inter-cohort variation in life history traits can help to explain individual performance in relation to conditions experienced by individuals born in the same year. For instance, individuals experiencing 'good' early life conditions may exhibit enhanced fitness compared to those exposed to 'poor' early life conditions, a facet of the so-called 'silver spoon' effect (Grafen, 1998; Cooke, Findlay \& Rockwell, 1984). Nevertheless, prevailing conditions encountered in later life (e.g., population density or weather during the breeding period) will also likely contribute to variation in cohortspecific life history traits because different cohorts experience different conditions during their 
76 potential breeding lifespan (Reid et al., 2003; Thessing \& Ekman, 1994; Reed et al., 2003).

77 Hence, favorable birth year effects may be offset if cohorts experience adverse conditions during subsequent breeding years. For example, in North American red squirrels (Tamiasciurus hudsonicus), silver spoon effects were diluted in cohorts that experienced lower food availability as adults (Descamps et al., 2008).

Breeding year conditions may be highly variable, particularly in Arctic regions (Martin \& Wiebe, 2004). For instance, breeding success in dark-bellied brent geese (Branta bernicla bernicla) is mainly dependent on lemming abundance (when predation pressure on geese is reduced because abundant lemmings provide alternative food sources for predators) and the onset of spring at the Arctic nesting grounds (Nolet et al., 2013). Recent cohorts have been exposed to a series of summers with low lemming abundance, so reproductive success and population size have declined (Nolet et al., 2013). Yet not all individuals breed in a given year, even during favorable breeding conditions (Sedinger et al., 2008). Whereas the highest quality individuals may always exploit the first opportunity to breed, lesser quality individuals may require several optimal years to gain condition before breeding, perhaps influenced by conditions experienced from one season to the next (termed 'carry-over effects'; Inger et al., 2010; Harrison et al., 2011). Carry-over effects may also affect fitness in cohorts of migrant birds, since pre-nesting body condition (which may be influenced by events extending back to previous winter conditions) was correlated with reproductive output and survival at the individual level (Ebbinge \& Spaans, 1995; Baker et al., 2004). Hence, the cumulative effects of prevailing conditions experienced by

97 a cohort from their collective maturity through to the point at which they successfully breed may have profound influence on the variation in age of first breeding among individuals in a given 
99

100

101

102

103

104

105

106

107

108

109

110

111

112

113

114

115

116

\section{Materials \& Methods}

\section{Study area and population}

119 From 1983 to 2003, 736 first-winter Greenland white-fronted geese were caught at Wexford

cohort. Understanding the degree to which these effects influence cohort variation in life history traits is therefore paramount in determining the relative importance of hatch year conditions, those experienced in adulthood prior to successful reproduction and those experienced in the year of successful reproduction.

Here, we used a 21-year dataset of repeated observations of individually marked, known-age Greenland white-fronted geese (Anser albifrons flavirostris) to determine whether cohort effects may be attributable to hatch year conditions, conditions experienced during adulthood in the years prior to successful reproduction and/or those experienced in the year of successful reproduction using commonly measured life history traits, including age at first successful reproduction (hereafter AFSR), the size of the first successful brood (SFSB) and the proportion of successful breeders by cohort (PSBC). We define 'cohort' as a group of hatch year birds marked during winter in a given year. We include environmental variables to reflect conditions experienced at each life stage. Greenland white-fronted geese are an ideal study species because they are relatively long lived (>15 years; Weegman et al., 2016) and encounter a variety of seasonal conditions throughout the year as they breed in west Greenland, stage during autumn and spring in Iceland and winter in Great Britain and Ireland (Fox et al., 2003, 2014). Slobs $\left(52^{\circ} 22^{\prime} \mathrm{N}, 6^{\circ} 24^{\prime} \mathrm{W}\right)$ under a ringing license (number A3136) granted to AJ Walsh from the British Trust for Ornithology. We truncated the dataset after the 2003 cohort (i.e., hatch year) to 
122 ensure adequate capture histories (i.e., compiled up to 2009) for later cohorts. Geese were caught

123 using standard cannon-netting techniques throughout winter on baited sites and individually

124 marked with a metal leg band, white plastic leg band and an orange neck collar (both bearing the

125 same unique alphanumeric code; see Warren et al., 1992), which complied with the requirements

126 of the National Parks and Wildlife Service (Ireland). Collar codes were legible with a 20-60x

127 spotting scope at up to $800 \mathrm{~m}$ distance. Individual geese were aged (juvenile or adult) by

128 plumage characteristics (presence/absence of white frons on face and black belly bars) and sexed

129 by cloacal examination (Warren et al., 1992; Cramp \& Simmons, 1977). AJ Walsh resighted

130 geese weekly at Wexford throughout all winters, beginning when birds arrived in autumn.

131 Importantly, we based all metrics of reproduction on resightings of marked Greenland white-

132 fronted geese during winter at Wexford. Therefore, our estimates of the SFSB, AFSR and PSBC

133 are contingent on juveniles surviving as goslings, fledging and migrating successfully to the

134 winter quarters.

135

136 Determining the size of the first successful brood

137 We determined the size of a successful brood when focal neck collared birds (with or without a

138 mate) were observed repeatedly ( $>2$ times) with juveniles during early winter (October-

139 December) at Wexford. In rare cases where brood sizes differed within a winter, we used the

140 mode. We used the SFSB instead of mean brood because very few birds were classified as

141 having bred successfully (i.e., observed on wintering areas with young) more than once.

143 Determining age at first successful reproduction and the proportion of 
145 We determined AFSR as the age at which a known-age individual was first repeatedly observed

146 ( $>2$ times within a winter at Wexford) as an adult, independent from its parents and with at least

147 one juvenile. We analyzed AFSR individually to investigate the relative contributions of hatch

148 year conditions, those experienced from adulthood prior to successful reproduction and those

149 experienced in the year of successful reproduction. We calculated the PSBC as the number of

150 birds observed with broods in a particular cohort divided by the total number of birds in that

151 cohort. The number of birds marked in each cohort varied from 72 birds in the 1985 cohort to 9

152 birds in the 2001 cohort (Fig. 1A).

153

\section{Environmental metrics}

155 We obtained North Atlantic Oscillation (NAO) data from the Climate Prediction Centre

156 (www.cpc.ncep.noaa.gov). The NAO is a cyclical weather phenomenon that is described by

157 pressure differences between the Azores and Iceland (Ottersen et al., 2001). Positive NAO

158 phases indicate low pressure over Iceland and increased frequency of severe storms crossing the

159 North Atlantic between Iceland and Scandinavia (Hurrell, 1995), whilst negative NAO phases

160 indicate the opposite effect (i.e., high pressure and weaker storm systems). However, in west

161 Greenland, positive NAO phases are typified by colder conditions and less precipitation, whereas

162 negative phases are characterized by warmer conditions and more precipitation (Stenseth et al.,

163 2003). We used mean NAO indices for May and December (Fig. 1B,C) as proxies for

164 environmental conditions at key points in the annual cycle (i.e., for pre-nesting foraging/nesting

165 conditions and those encountered during winter in Great Britain and Ireland), which we predicted

166 would exert the greatest influence on fitness proxies across cohorts of Greenland white-fronted

167 geese. In North America, positive spring and summer NAO indices have been correlated with 
168 declines in reproductive output of Arctic-nesting greater snow geese (Chen caerulescens 169 atlanticus; Morrissette et al., 2010) and light-bellied brent geese (B. bernicla hrota; Harrison et 170 al., 2013); however, in Greenland white-fronted geese, we would expect that positive May NAO

171 indices would result in favorable breeding conditions (i.e., cold and dry) in west Greenland.

172 December NAO indices may predict reproductive output during the following summer because

173 environmental conditions during winter have been shown to contribute to explaining arrival date 174 on breeding areas (Saino et al., 2004a), and breeding probability (Sedinger et al., 2008; Sedinger 175 et al., 2011) and success (Saino et al., 2004b) in birds. Therefore, we would expect that cohorts 176 which experience more positive May NAO indices in Greenland (i.e., colder and drier 177 conditions) and negative December NAO indices on wintering areas (i.e., less storms) during 178 their potential breeding lives would first reproduce successfully at younger ages, have larger 179 broods and more successful breeders per cohort.

To determine whether environmental conditions experienced by cohorts through adulthood and prior to successful reproduction explained variation in AFSR and SFSB, we developed a 'breeding conditions index' (BCI) and used annual May NAO indices as a proxy for environmental conditions experienced during the breeding season (see Environmental metrics for description of May NAO). We calculated the mean May NAO indices to which individuals were exposed from age 2 (i.e., reproductive maturity) to one year prior to successful reproduction. The $\mathrm{BCI}$ aims to describe the cumulative conditions during the sequence of annually variable breeding opportunities to which each individual was exposed. Increasingly positive BCI scores imply exposure to a series of years with more favorable breeding conditions and increasingly negative $\mathrm{BCI}$ scores indicate more years of adverse breeding conditions. By using May NAO for 
191 calculation of the BCI and as a proxy for hatch and breeding year conditions, we were able to

192 examine the influence of such conditions during each life stage on variation in AFSR and SFSB

193 among individuals.

194

195 To investigate whether variation in the PSBC was explained by the set of environmental

196 conditions each cohort experienced over its potential reproductive lifetime, we developed a

197 similar index, the 'cohort breeding conditions index' (CBCI). We calculated CBCI scores using

198 May NAO indices based on a rolling average for the years from reproductive maturity (age 2) to

199 age 10 for each cohort (e.g., the CBCI for an age 5 bird was the average of May NAO indices at

200 ages 2-5). The CBCI scores declined from the 1983 cohort to the 2003 cohort (Fig. 1D). An

201 important difference between the $\mathrm{BCI}$ and $\mathrm{CBCI}$ is that the $\mathrm{CBCI}$ is calculated through age 10

202 for all cohorts (i.e., it is not truncated by successful reproduction) and is therefore a proxy for the

203 overall set of environmental conditions to which each cohort was exposed throughout adulthood,

204 where mean positive CBCI scores indicate 'better' breeding conditions across a cohort's adult

205 life. By including the CBCI in analyses of the PSBC, we are able to better understand the

206 environmental patterns influencing 'successful' and 'unsuccessful' cohorts, namely whether

207 'poor' conditions prevailing throughout the reproductive life of a cohort resulted in fewer

208 successful breeders. We limited the CBCI to age 10 because incubation and brood-rearing

209 success in geese significantly decreases beyond this age (Rockwell et al., 1993).

211 Statistical analyses

212 We performed all analyses examining variation in the AFSR, SFSB and PSBC in Program R,

213 version 2.14.2 (R Development Core Team, 2012). We assessed multicollinearity among 
214 variables by calculating variance inflation factors using the HH package (Heiberger, 2016); no

215 variables had scores $>3$, hence, multicollinearity was minimal (see Cade, 2015).

216

217 To determine the relative contributions of hatch year conditions, those experienced during

218 adulthood prior to the year of successful reproduction and those experienced in the year of

219 successful reproduction on AFSR and SFSB, we fitted generalized linear mixed models with

220 Poisson error distributions and log link functions using the lme4 package (Bates et al., 2014) and

221 included year of successful reproduction as a random intercept (i.e., to account for unexplained

222 variation between cohorts) and hatch year May NAO, May NAO in the year of successful

223 reproduction, December NAO in the winter prior to successful reproduction and the BCI (i.e.,

224 average May NAO from adulthood prior to the year of successful reproduction) as fixed effects

225 in models of AFSR and SFSB (Table 1). We included logical (i.e., interpretable) two-way

226 interactions in the models. After initial models of AFSR and SFSB, we removed the random

227 effect of year at first successful reproduction because it explained zero variance. We completed

228 further analyses of fixed effects using generalized linear models.

230 For each potential year of successful reproduction, the response for models of the PSBC was ' 1 '

231 or ' 0 ' dependent on whether any bird from that particular cohort successfully bred in that year.

232 We included cohort size $(n)$ as an offset in all models to reduce bias towards larger cohorts. We

233 fitted generalized linear mixed models using a logit link function and binomial error distribution

234 and included cohort (i.e., hatch year) and potential year of successful reproduction (i.e., for ages

235 2-10) as random intercepts, and May NAO during the year of successful reproduction, December

$236 \mathrm{NAO}$ in the winter prior to successful reproduction, cohort size and CBCI as fixed effects. We 
237 fitted cohort size as an interaction with all explanatory variables to account for the relationship

238 between the ratio of successful breeders and cohort size. We also fitted other logical two-way

239 interactions in models.

240

241 We selected top models using Akaike's information criterion (AICc; through the MuMIn

242 package in R; Barton, 2013), corrected for small sample sizes ( $\triangle \mathrm{AICc}<6$; Burnham \&

243 Anderson, 2002; Richards, 2008), and standardized coefficients by their partial standard

244 deviations (to ensure a common denominator in model selection and account for any small

245 collinearity between variables in each model; Barton, 2013; Cade, 2015). We calculated model-

246 averaged coefficients for the revised model set. We applied the nesting rule (i.e., removed

247 complex models with greater AICc values, in favor of simpler models that shared one or more of

248 the same terms) to the top model set, eliminating so-called 'uninformative parameters' (Arnold,

249 2010). To examine model fit, we calculated Nagelkerke $\mathrm{R}^{2}$ values for retained models in the top

250 set (or the full model containing all fixed effects if models did not differ from the null;

251 Nagelkerke, 1991). The relative importance of each variable was calculated as the ratio of the

252 model-averaged coefficient divided by its standard error (Cade, 2015).

253

254 Results

255 From the cohorts hatched between 1983 and 2003, 59 (8\%) of 736 marked Greenland white-

256 fronted geese reproduced successfully only once (i.e., were repeatedly observed within a winter

257 with young at Wexford). Just 13 birds successfully reproduced twice and two birds successfully

258 reproduced three times (Fig. 2). No juvenile geese were marked in 2000; thus this cohort could

259 not be included in the analysis. No geese from the 1996 (cohort $n=25), 1999(n=15)$ and 2003 
$260(n=40)$ cohorts ever reproduced successfully (i.e., no birds from these cohorts were observed

261 repeatedly with young during winter at Wexford). Among cohorts with birds that successfully

262 reproduced, cohort size varied from 9 birds (2001 cohort) to 72 birds (1985 cohort).

263

264 Size of the first successful brood

265 Modal SFSB among ages at first successful reproduction ranged from 2 at ages 6 (min. $=1$, $\max$. $266=2 ; n$ broods $=3), 7(\min .=2, \max .=4 ; n$ broods $=6)$ and $10(\min$. and $\max .=2 ; n$ broods $=2)$

267 to 4 at ages $2(\min .=1, \max .=5 ; n$ broods $=9)$ and $8(\operatorname{mini} .=2, \max .=4 ; n$ broods $=4)$.

268 Among cohorts, modal SFSB was greatest $(\operatorname{modal}$ brood size $=4)$ in the $1985(\min .=3$, $\max .=$

$2696 ; n$ broods $=9), 1987(\min .=1, \max .=4 ; n$ broods $=3)$ and $1988(\min$. and $\max .=4 ; n$ broods

$270=2$ ) cohorts and smallest (modal brood size $=1)$ in the 1986 cohort $(\min .=1$, max. $=4 ; n$ broods

$271=8$ ). The 'full' model (i.e., incorporating all fixed effects; Table 1) explaining variation in SFSB

272 did not differ from the null (Nagelkerke $\mathrm{R}^{2}=0.03$ ), indicating that the fixed effects we examined

273 did not explain a significant amount of the among-individual variation.

274

275 Age at first successful reproduction

276 Mean AFSR among cohorts ranged from 2-years-old (1988 cohort $n$ breeders $=2$ ) to 8-years-old

277 (1990 cohort $n$ breeders =5; Fig. S1). Using the nesting rule, we retained four models from the

278 top model set $(\triangle \mathrm{AICc}<6)$ that included hatch year May NAO, the BCI and a two-way

279 interaction between the BCI and May NAO in the year of successful reproduction (Nagelkerke

$280 \mathrm{R}^{2}$ estimate of top retained model $=0.25$; Table 2 ), but did not include December NAO prior to

281 successful reproduction. Model-averaged estimates for the standardized coefficients are

282 presented in Table 3. The BCI was the only effect to occur in all four retained models, and its 
283 relative importance (3.49; Table 3 ) was three times that of hatch year May NAO and the two way

284 interaction between the BCI and May NAO in the year of successful reproduction (relative

285 importance $=1.22$ and 1.16, respectively). Thus, variation in AFSR was explained primarily by

286 conditions that birds experienced from adulthood prior to the year of successful reproduction,

287 whereby birds that experienced 'good' conditions from adulthood prior to the year of successful

288 reproduction reproduced at youngest ages (i.e., age 4; Fig. 3), but those that experienced 'poor'

289 conditions in adulthood reproduced at oldest ages (i.e., age 7) among the birds in this study.

290

291 Variation in AFSR was also explained by a weak relationship with hatch year environmental

292 conditions, where birds that hatched in years with 'good' conditions (i.e., positive May NAO)

293 successfully reproduced at earlier ages (Fig. S2A), although the effect size (standardized

294 coefficient $-0.07,95 \%$ confidence interval (CI) $-0.20,0.01$ ) was marginally significant and less

295 than that of the BCI (coefficient $-0.19,95 \%$ CI $-0.29,-0.08$ ). Similarly, variation in AFSR was

296 explained by a weak two-way interaction between the BCI and conditions experienced in the

297 year of successful reproduction (coefficient $-0.09,95 \%$ CI $-0.24,-0.03$ ), where conditions

298 experienced in the year of successful reproduction determined the importance of conditions

299 experienced previously in adulthood (Fig. S2B). Birds that experienced 'good' conditions in the

300 year of successful reproduction and 'good' conditions from adulthood prior to the year of

301 successful reproduction successfully bred at youngest ages (i.e., age 3; Fig. S2B). Birds that

302 experienced 'good' conditions in the year of successful reproduction and 'poor' conditions in

303 adulthood successfully bred at oldest ages (i.e., age 9). Nonetheless, we caution interpretation of

304 results for hatch year conditions and the two-way interaction between the BCI and conditions in 
305 the year of the successful reproduction because coefficient estimates were very small (and their $30695 \%$ CIs were near zero).

307

\section{Proportion of successful breeders by cohort}

309 The proportion of each cohort that successfully returned to Wexford with young (i.e., were considered successful breeders) was greatest in the 2001 cohort (22\% successful breeders) and least in the 1996, 1999 and 2003 cohorts (no successful breeders; Fig. S3). The variance explained by the cohort random intercept (0.14, standard deviation (SD) 0.38 ) was small and less than that of the potential breeding year (2.22, SD 1.49). Our full model explaining variation in the PSBC did not differ from the null (Nagelkerke $\mathrm{R}^{2}=0.11$ ); thus we could not explain whether variation in hatch year conditions, those experienced from adulthood prior to successful reproduction or those experienced in the year of successful reproduction influenced the PSBC.

\section{Discussion}

Life histories of known-age individually marked Greenland white-fronted geese showed that only $10 \%$ of these individuals ever reproduce successfully and very few $(2 \%)$ reproduced successfully more than once during their lifetime. Variation in AFSR was explained primarily by environmental conditions experienced during adulthood prior the year of successful reproduction. When birds experienced good conditions (i.e., cool and dry, positive May NAO) in adulthood prior to the year of successful reproduction, they reproduced at youngest ages. When birds experienced poor conditions (i.e., warm and wet, negative May NAO) in adulthood prior to the year of successful reproduction they reproduced at oldest ages. The influence of conditions in the year of successful reproduction on breeding success of Arctic-nesting birds has been 
328 documented in other populations (e.g., in lesser snow geese (C. caerulescens caerulescens) and

329 Atlantic brant (B. bernicla hrota); Davies \& Cooke, 1983; Skinner et al., 1998; Barry, 1962) and

330 in this population (Boyd \& Fox, 2008). However, we are unaware of previous studies that

331 evaluated conditions experienced in adulthood prior to the year of successful reproduction to

332 understand their collective impact on life history traits.

334 We could not explain variation in the SFSB through environmental variables measured during

335 hatch year, adulthood prior to the year of successful reproduction or in the year of successful

336 reproduction. Thus, we could not link conditions in adulthood prior to successful reproduction,

337 which explained significant variation in AFSR, with those that explained variation in the SFSB.

338 This suggests that environmental conditions influenced successful breeding, but not the size of

339 the successful brood (i.e., birds experienced either good conditions and produced similar-sized

340 broods, or poor conditions and did not successfully produce a brood). Alternatively, with only 74

341 successful breeders in 27 years in this study, it is possible that our sample was too small to

342 explain variation in the SFSB or that factors other than those we examined here influenced the

343 remaining variation in the SFSB.

Similarly, we could not attribute variation in the PSBC to the environmental conditions

variation in the PSBC, which suggests that we did not identify all potential sources of the

variation. Individual heterogeneity could determine whether individuals from a given cohort (i.e.,

which experience the same environmental conditions) successfully reproduced (Barbraud \&

350 Weimerskirch, 2005) particularly if they experienced average or poor environmental conditions 
351 from adulthood prior to successful reproduction. For example, because of carry-over effects

352 (Harrison et al., 2011), within a given cohort, high quality individuals may successfully

353 reproduce under average environmental conditions, whereas poor quality individuals may either

354 require multiple years of average and/or good environmental conditions to attain successful

355 reproduction, or never successfully reproduce, despite average or good environmental

356 conditions. In addition, analyses examining other factors at 'important' points in the annual cycle

357 (e.g., nutrient acquisition during spring migration, which is known to influence reproductive

358 success in migrant birds; Weber, Ens \& Houston, 1998; Prop, Black \& Shimmings, 2003) are

359 needed to better understand patterns in the PSBC.

361 A potential source of bias in our study is the imperfect detection of individuals at their main 362 wintering site (Wexford, Ireland), as not all collared individuals were resighted in every year of

363 their lifetime. Thus, some birds may have successfully reproduced (i.e., returned to Wexford 364 with young), but not been detected either individually or with their brood. To assess this bias, we 365 filtered our data set to include only individuals that were seen in every year after marking until 366 the end of their capture histories (i.e., those considered 'perfectly' resighted), when they either 367 permanently emigrated or died. In total, 549 of the 736 birds (and 41 of 74 successful breeders) 368 included this study were 'perfectly' resighted. Results from similar models of AFSR, SFSB and 369 PSBC matched those found in analyses of all birds, specifically that the BCI explained 370 significant variation in AFSR, where birds successfully reproduced at youngest ages when 371 conditions in adulthood were 'good' (see Table S1). Importantly, no other effects explained

372 variation in AFSR, and no effects explained significant variation in the SFSB or PSBC. These

373 results suggest that any potential bias associated with the imperfect detection of successful 
374 breeding individuals is minimal and unlikely to influence results and inferences drawn from our

375 analyses incorporating all individuals.

376

377 Here, we have demonstrated that variation in AFSR among individual Greenland white-fronted geese was explained by the conditions birds experienced from adulthood prior to the year of successful reproduction. Since $90 \%$ of successful breeders brought young back to Wexford only once in their lifetime, these environmental conditions equate to factors influencing not only AFSR, but effectively lifetime reproductive success. Thus, the ultimate fitness of most individuals was dependent on these conditions. In this population, fitness advantages to reproducing successfully earlier seem unclear, because even those that reproduced successfully earlier in life rarely did so again (in contrast to individuals of other species that commonly successfully reproduce across multiple years; Newton, 1989; Cooke, Lank \& Rockwell, 1995; Krüger \& Lindström, 2001). However, classic life history theory predicts that for every year in which birds fail to reproduce successfully, they risk dying with zero fitness (inclusive fitness notwithstanding; Hamilton, 1964). Thus, individuals yet to have reproduced successfully must balance the risk of dying in the next year with reproductive attempts in variable (and increasingly suboptimal) environmental conditions. Indeed, over our study period, poor conditions became more frequent; from 1983 to 1992, a negative May NAO phase occurred in just three years, but in seven years from 1993 to 2002 and in five years from 2003 to 2012, which may explain the recent decline in productivity in this population, and the 'sink' status of the Wexford subpopulation (Weegman et al., 2016). Even when cohorts were exposed to good breeding year conditions, many that experienced poor conditions from adulthood reproduced later. Hence, in recent years, there have been fewer years of good breeding conditions and individuals that lived 
397 through these years were exposed to a cumulative negative effect, which caused successful

398 reproduction at older ages. That individuals in cohorts experienced the same hatch year

399 conditions and similar conditions from adulthood prior to successful reproduction indicates these

400 should be studied as cohort effects. Thus, we build on previous studies which concluded that

401 environmental conditions during hatch/birth year influenced fitness of individuals in cohorts

402 (e.g., in red-billed choughs (Pyrrhocorax pyrrhocorax; Reid et al., 2003), greater snow geese

403 (Reed et al., 2003), Soay sheep (Forchhammer et al., 2001) and red deer (Cervus elaphus; Rose,

404 Clutton-Brock \& Guinness, 1998) by showing that conditions from adulthood prior to successful

405 reproduction also influence the age at which individuals first successfully reproduce (and

406 determine the ultimate fitness in this population).

407

\section{Acknowledgements}

409 We thank the National Parks and Wildlife Service of Ireland, particularly the offices of J.

410 Wilson, D. Norriss, O. Merne and D. Tierney for their support. We thank the many volunteers

411 who have helped catch and mark Greenland white-fronted geese at Wexford over the study

412 period, especially P. O’Sullivan and the late C. Wilson. We also thank D. Koons, X. Harrison, G.

413 Souchay, T. Arnold and K. Weegman for their helpful comments to earlier versions of this

414 manuscript. Finally, we thank our respective employers for their support of this research.

416 References

417 Arnold TW. 2010. Uninformative parameters and model selection using Akaike's information criterion. Journal of Wildlife Management 74:1175-1178. 
419

420

421

422

423

424

425

426

427

428

429

430

431

432

433

434

435

436

437

438

439

440

Baker AJ, Gonzalez PM, Piersma T, Niles LJ, do Nascimento IDS, Atkinson PW, Clark NA, Minton CDT, Peck MK, Aarts G. 2004. Rapid population decline in red knots: fitness consequences of decreased refuelling rates and late arrival in Delaware Bay. Proceedings of the Royal Society of London Series B-Biological Sciences 271:875882.

Barbraud C, Weimerskirch H. 2005. Environmental conditions and breeding experience affect costs of reproduction in blue petrels. Ecology 86:682-692.

Barry TW. 1962. Effect of late seasons on Atlantic brant reproduction. Journal of Wildlife Management 26:19-26.

Barton K. 2013. MuMIn: multi-model inference. R package version 1.9.13.

Bates D, Maechler M, Bolker B, Walker S. 2014. lme4: Linear mixed-effects models using Eigen and S4. R package version 1.1-6.

Boyd H, Fox AD. 2008. Effects of climate change on the breeding success of white-fronted geese Anser albifrons flavirostris in west Greenland. Wildfowl 58:55-70.

Burnham KP, Anderson DR. 2002. Model selection and multimodel inference, 2nd edn. New York: Springer-Verlag.

Cade BS. 2015. Model averaging and muddled multimodel inferences. Ecology 96:2370-2382.

Coltman DW, Smith JA, Bancroft DR, Pilkington J, MacColl ADC, Clutton-Brock TH, Pemberton JM. 1999. Density-dependent variation in lifetime breeding success and natural and sexual selection in Soay rams. The American Naturalist 154:730-746.

Cooke F, Findlay CS, Rockwell RF. 1984. Recruitment and the timing of reproduction in lesser snow geese (Chen caerulescens caerulescens). Auk 101:451-458. 
441 Cooke F, Lank DB, Rockwell RF. 1995. The snow geese of La Perouse Bay: natural selection

442 in the wild. Oxford: Oxford University Press.

443 Cramp S, Simmons KEL. 1977. The birds of the western Palearctic, Vol. 1. Oxford: Oxford $444 \quad$ University Press.

445 Davies JC, Cooke F. 1983. Annual nesting productivity in snow geese: prairie droughts and 446 Arctic springs. Journal of Wildlife Management 47:291-296. 
464 Grafen A. 1988. On the uses of data on lifetime reproductive success. In: Clutton-Brock TH, ed. 465 Reproductive success: studies of individual variation in contrasting breeding systems. 466 Chicago: University of Chicago Press, 454-471.

467 Hamilton WD. 1964. The genetical evolution of social behaviour. Journal of Theoretical $468 \quad$ Biology 7:1-52.

469 Harrison XA, Blount JD, Inger R, Norris DR, Bearhop S. 2011. Carry-over effects as drivers 470 of fitness differences in animals. Journal of Animal Ecology 80:4-18.

471

472

473

474

475

476

477

478

479

480

481

482

483

484

\section{Harrison XA, Hodgson DJ, Inger R, Colhoun K, Gudmundsson GA, McElwaine G,} Tregenza T, Bearhop S. 2013. Environmental conditions during breeding modify the strength of mass-dependent carry-over effects in a migratory bird. PLoS ONE 8: e77783.

Heiberger RM. 2016. HH: Statistical analyses and data display: Heiberger and Holland. R package version 3.1-25.

Hurrell J. 1995. Decadal trends in the North Atlantic Oscillation: regional temperatures and precipitation. Science 269:676-679.

Inger R, Harrison XA, Ruxton GD, Newton J, Colhoun K, Gudmundsson GA, McElwaine G, Pickford M, Hodgson D, Bearhop S. 2010. Carry-over effects reveal reproductive costs in a long-distance migrant. Journal of Animal Ecology 79:974-982.

Krüger O, Lindström J. 2001. Lifetime reproductive success in common buzzard, Buteo buteo: from individual variation to population demography. Oikos 93:260-273.

Lindström J. 1999. Early development and fitness in birds and mammals. Trends in Ecology and Evolution 14:343-348. 
485 Martin K, Wiebe KL. 2004. Coping mechanisms of alpine and arctic breeding birds: extreme

486

487

488

489

490

491

492

493

494

495

496

497

498

499

500

501

502

503

504

505

506

507 weather and limitations to reproductive resilience. Integrative and Comparative Biology 44:97-105.

Morrissette M, Bety J, Gauthier G, Reed A, Lefebvre J. 2010. Climate, trophic interactions, density dependence and carry-over effects on the population productivity of a migratory Arctic herbivorous bird. Oikos 119:1181-1191.

Nagelkerke NJD. 1991. A note on a general definition of the coefficient of determination. Biometrika 78:691-692.

Newton I. 1989. Lifetime reproduction in birds. London: Academic Press.

Nolet BA, Bauer S, Feige N, Kokorev YI, Popov IY, Ebbinge BS. 2013. Faltering lemming cycles reduce productivity and population size of a migratory Arctic goose species. Journal of Animal Ecology 82:804-813.

Ottersen G, Planque B, Belgrano A, Post E, Reid PC, Stenseth NC. 2001. Ecological effects of the North Atlantic Oscillation. Oecologia 128:1-14.

Prop J, Black JM, Shimmings P. 2003. Travel schedules to the high Arctic: barnacle geese trade-off the timing of migration with accumulation of fat deposits. Oikos 103:403-414.

R Development Core Team. 2012. $R$ : A language and environment for statistical computing. Vienna: R Foundation for Statistical Computing.

Reed ET, Gauthier G, Pradel R, Lebreton J-D. 2003. Age and environmental conditions affect recruitment in greater snow geese. Ecology 84:219-230.

Reid JM, Bignal EM, Bignal S, McCracken DI, Monaghan P. 2003. Environmental variability, life-history covariation and cohort effects in the red-billed chough Pyrrhocorax pyrrhocorax. Journal of Animal Ecology 72:36-46. 
508 Richards SA. 2008. Dealing with overdispersed count data in applied ecology. Journal of $509 \quad$ Applied Ecology 45:218-227.

510 Rockwell RF, Cooch EG, Thompson CB, Cooke F. 1993. Age and reproductive success in 511 female lesser snow geese: experience, senescence and the cost of philopatry. Journal of $512 \quad$ Animal Ecology 62:323-333.

513 Rose KE, Clutton-Brock TH, Guinness FE. 1998. Cohort variation in male survival and 514 lifetime breeding success in red deer. Journal of Animal Ecology 67:979-986.

515 Sæther B-E. 1997. Environmental stochasticity and population dynamics of large herbivores: a 516 search for mechanisms. Trends in Ecology and Evolution 12:143-149.

Saino N, Szep T, Ambrosini R, Romano M, Moller AP. 2004b. Ecological conditions during winter affect sexual selection and breeding in a migratory bird. Proceedings of the Royal Society of London Series B-Biological Sciences 271:681-686.

Saino N, Szep T, Romano M, Rubolini D, Spina F, Moller AP. 2004a. Ecological conditions during winter predict arrival date at the breeding quarters in a trans-Saharan migratory bird. Ecology Letters 7:21-25.

Sedinger JS, Chelgren ND, Lindberg MS, Ward DH. 2008. Fidelity and breeding probability related to population density and individual quality in black brent geese (Branta bernicla nigricans). Journal of Animal Ecology 77:702-712.

Sedinger JS, Schamber JL, Ward DH, Nicolai CA, Conant B. 2011. Carryover effects associated with winter location affect fitness, social status, and population dynamics in a long-distance migrant. The American Naturalist 178:E110-E123. 
529 Skinner WR, Jeffries RL, Carleton TJ, Rockwell RF, Abraham KF. 1998. Prediction of 530 reproductive success and failure in lesser snow geese based on early season climatic

531

532

533

534

535

536

537

538

539

540

541

542

543

544

545

546

547

548

549

550

551 variables. Global Change Biology 4:3-16.

Stenseth NC, Ottersen G, Hurrell JW, Mysterud A, Lima M, Chan K-S, Yoccoz NG, Adlandsvik B. 2003. Studying climate effects on ecology through the use of climate indices: the North American Oscillation, El Nino Southern Oscillation and beyond. Proceedings of the Royal Society of London Series B-Biological Sciences 270:2087-2096.

Thessing A, Ekman J. 1994. Selection of the genetical and environmental components of tarsal growth in juvenile willow tits (Parus montanus). Journal of Evolutionary Biology 7:713726.

van der Jeugd HP, Larsson K. 1998. Pre-breeding survival of barnacle geese Branta leucopsis in relation to fledgling characteristics. Journal of Animal Ecology 67:953-966.

Warren SM, Fox AD, Walsh A, O'Sullivan P. 1992. Age at first pairing and breeding among Greenland white-fronted geese. Condor 94:791-793.

Weber TP, Ens BJ, Houston AI. 1998. Optimal avian migration: a dynamic model of fuel stores and site use. Evolutionary Ecology 12:377-401.

Weegman MD, Bearhop S, Fox AD, Hilton GM, McDonald JL, Hodgson DJ. 2016. Integrated population modelling reveals a perceived source to be a cryptic sink. Journal of Animal Ecology 85:467-475.

\section{Figure Legends}

Figure 1. Environmental variables used in analyses of age at first successful reproduction, size of the first successful brood and the proportion of successful breeders by cohort. 
552

553

554

555

556

557

558

559

560

561

562

563

564

565

566

567

568

569

570

571

572

573

574 Table Legends

(A) Greenland white-fronted goose cohort sample size (n), 1983-2003. All geese were marked in their first winter (i.e., were known age). Mean annual monthly (B) May NAO and (C) December NAO. These parameters were included in generalized linear mixed models of age at first successful reproduction and size of the first successful brood. (D) Cohort breeding conditions index (CBCI) by year, 1983-2003. The CBCI was calculated using May NAO indices and based on a rolling average for the years from reproductive maturity (age 2) to age 10 for each cohort, and was included in a generalized linear mixed model of the proportion of successful breeders by cohort. Positive CBCI values indicated 'good' environmental conditions across the reproductive lifetime of a cohort, whilst negative CBCI values indicated the opposite effect (i.e., poor environmental conditions). For all plots, lines were fitted using regression models with linear and quadratic terms.

Figure 2. The proportion of successful broods per bird ( $n$ subset indicated above bars) produced in the lifetimes of 736 Greenland white-fronted geese marked as first year birds at Wexford, Ireland, 1983-2003.

Figure 3. Age at first successful reproduction among Greenland white-fronted geese (19832003) as a function of the breeding conditions index (BCI). The BCI was based on averaged May NAO indices from the time birds reached reproductive maturity (age 2) through one year prior to successful reproduction, where positive BCI values indicated 'good' conditions and negative values 'poor' conditions. 
575 Table 1. Model structure to examine whether variation in age at first successful reproduction

576 (AFSR), size of the first successful brood (SFSB) and proportion of successful breeders by

577 cohort (PSBC) was due to hatch year (HY) effects, conditions prior to successful reproduction

578 (breeding conditions index; BCI) or those experienced in the year of successful reproduction 579 (BY).

580

Table 2. Top model set $(\triangle \mathrm{AICc}<6)$ explaining variation in age at first successful reproduction across cohorts 1983-2003 among Greenland white-fronted geese. After the nesting rule was applied (Richards, 2008), we retained four models (indicated by a ' $\checkmark$ ').

584

585

Table 3. Model-averaged estimate, 95\% confidence intervals (CI) and relative importance for 586 fixed effects in the top model set explaining variation in age at first successful reproduction in Greenland white-fronted goose cohorts 1983-2003.

\section{Supplemental Figure and Table Legends}

590

591

592

593

594

595

596

597

Figure S1. Age at first successful reproduction $( \pm \mathrm{SE})$ across Greenland white-fronted goose cohorts, 1983-2003.

\section{Figure S2. Age at first successful reproduction among Greenland white-fronted geese} (1983-2003) as a function of (A) hatch year May NAO and (B) the two-way interaction between the breeding conditions index (BCI) and breeding year May NAO. The BCI was based on averaged May NAO indices from the time birds reached reproductive maturity (age 2) through one year prior to successful reproduction, where 
598

599

600

601

602

603

604

605

606

607

608

609 positive BCI values indicated 'good' conditions and negative values 'poor' conditions.

Breeding year conditions were split by the mean $(\bar{x}=0$; average conditions $)$, first $(-1.25$;

poor conditions) and third (1.00; good conditions) quartiles of the continuous May NAO distribution.

Figure S3. The proportion of successful breeders by cohort ( $n$ breeders indicated at each point) in Greenland white-fronted geese marked at Wexford, Ireland, 1983-2003.

Table S1. Model-averaged estimate, 95\% confidence intervals (CI) and relative importance for

fixed effects in the top model set explaining variation in age at first successful reproduction among perfectly resighted Greenland white-fronted geese 1983-2003 (i.e., including only birds seen in every year of their capture history before either death or permanent emigration). 


\section{1}

Environmental variables used in analyses of age at first successful reproduction, size of the first successful brood and the proportion of successful breeders by cohort.

\section{Environmental variables used in analyses of age at first successful reproduction,} size of the first successful brood and the proportion of successful breeders by cohort. (A) Greenland white-fronted goose cohort sample size (n), 1983-2003. All geese were marked in their first winter (i.e., were known age). Mean annual monthly (B) May NAO and (C) December NAO. These parameters were included in generalized linear mixed models of age at first successful reproduction and size of the first successful brood. (D) Cohort breeding conditions index (CBCl) by year, 1983-2003. The CBCl was calculated using May NAO indices and based on a rolling average for the years from reproductive maturity (age 2) to age 10 for each cohort, and was included in a generalized linear mixed model of the proportion of successful breeders by cohort. Positive CBCl values indicated 'good' environmental conditions across the reproductive lifetime of a cohort, whilst negative $\mathrm{CBCl}$ values indicated the opposite effect (i.e., poor environmental conditions). For all plots, lines were fitted using regression models with linear and quadratic terms. 

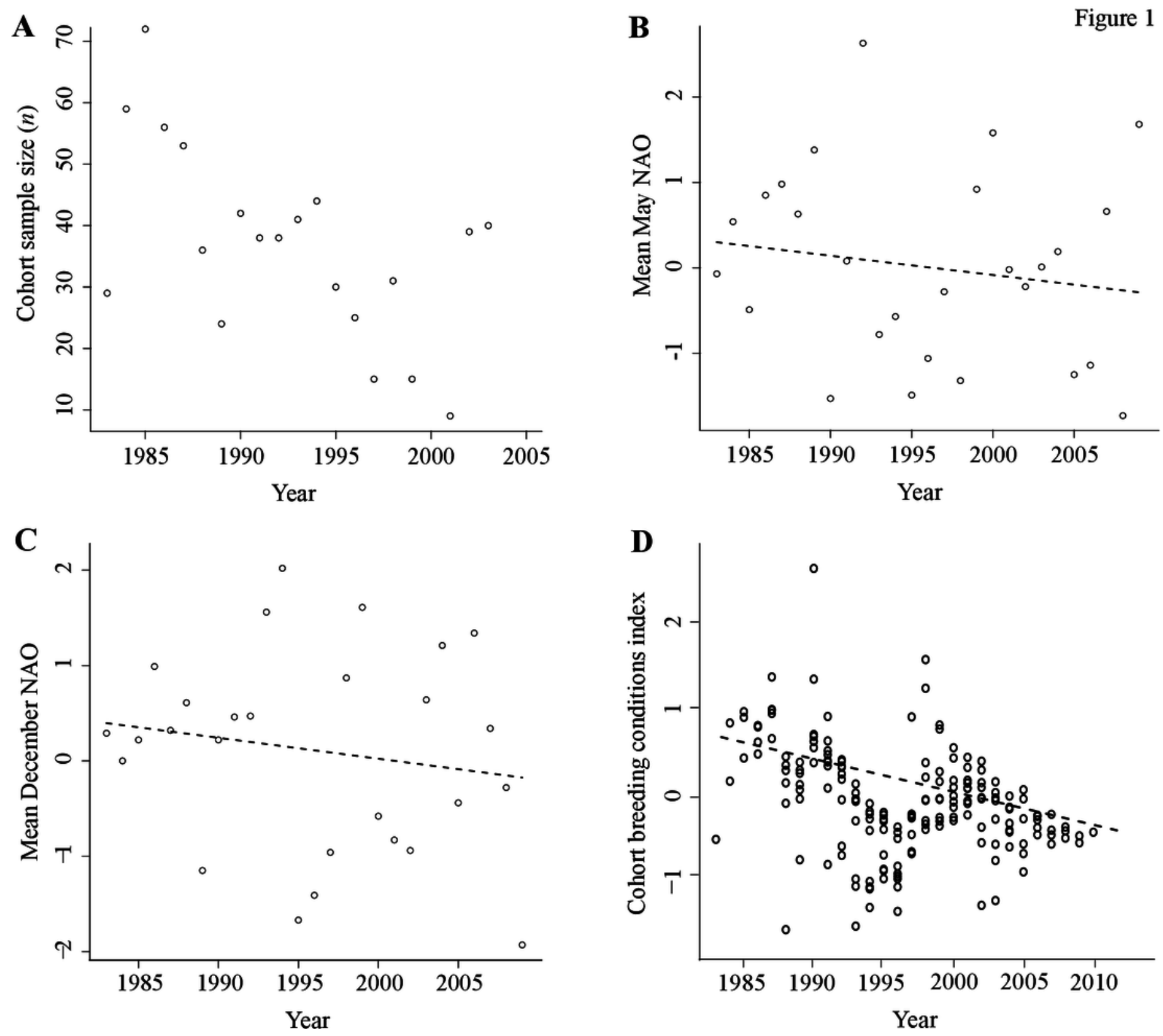
2

The proportion of successful broods per bird.

The proportion of successful broods per bird ( $n$ [i] subset indicated above bars) produced in the lifetimes of 736 Greenland white-fronted geese marked as first year birds at Wexford, Ireland, 1983-2003. 


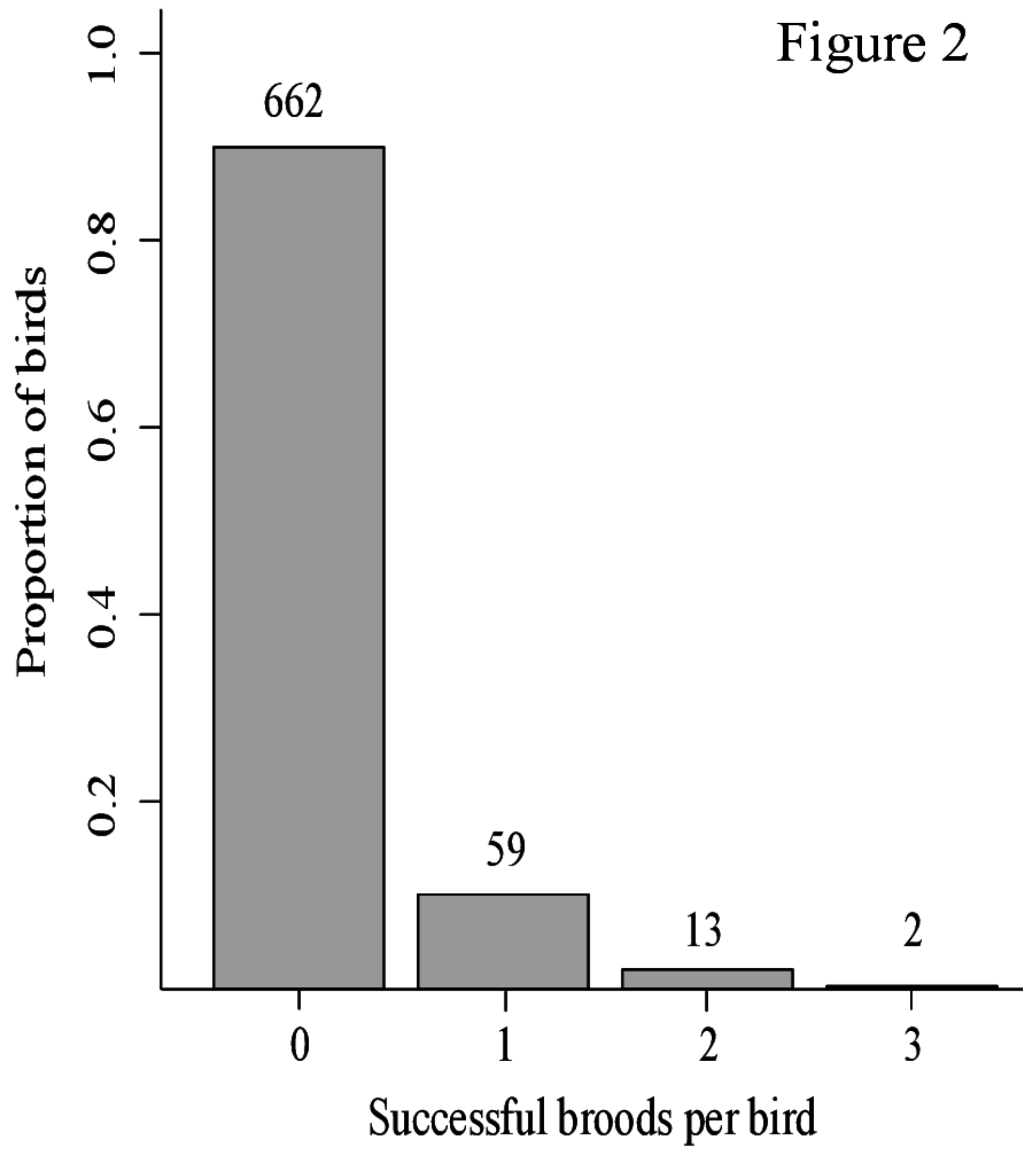


3

Age at first successful reproduction among Greenland white-fronted geese (1983-2003) as a function of the breeding conditions index $(\mathrm{BCl})$.

Age at first successful reproduction among Greenland white-fronted geese (1983-2003) as a function of the breeding conditions index $(\mathrm{BCl})$. [b]The $\mathrm{BCl}$ was based on averaged May NAO indices from the time birds reached reproductive maturity (age 2) through one year prior to successful reproduction, where positive $\mathrm{BCl}$ values indicated 'good' conditions and negative values 'poor' conditions. 


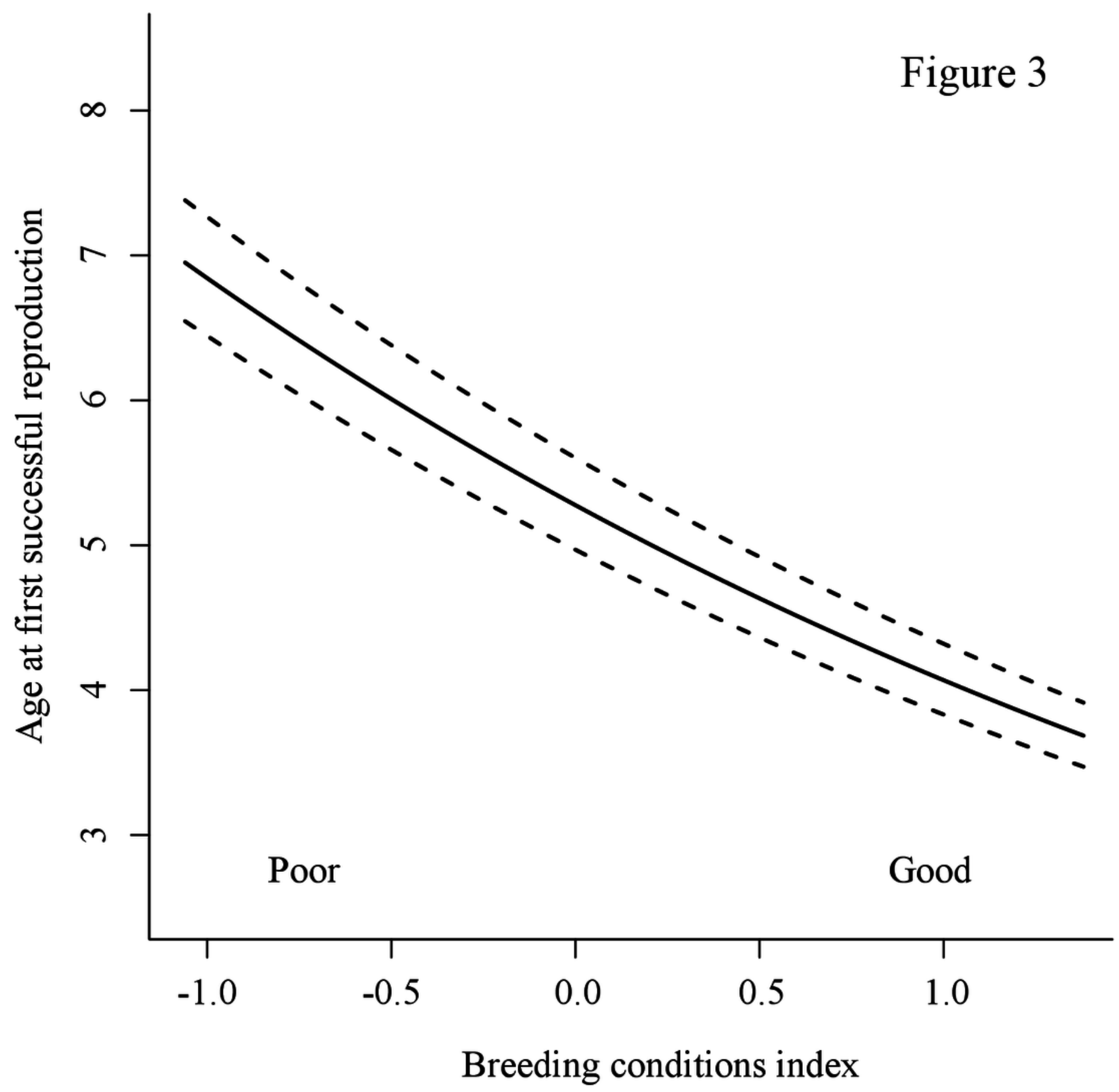




\section{Table $\mathbf{1}$ (on next page)}

Model structure to explain variation in age at first successful reproduction (AFSR), size of the first successful brood (SFSB) and proportion of successful breeders by cohort (PSBC)

Model structure to examine whether variation in age at first successful reproduction (AFSR), size of the first successful brood (SFSB) and proportion of successful breeders by cohort (PSBC) was due to hatch year (HY) effects, conditions prior to successful reproduction (breeding conditions index; $\mathrm{BCl}$ ) or those experienced in the year of successful reproduction (BY). 
1 Table 1. Model structure to examine whether variation in age at first successful reproduction

2 (AFSR), size of the first successful brood (SFSB) and proportion of successful breeders by

3 cohort (PSBC) was due to hatch year (HY) effects, conditions prior to successful reproduction

4 (breeding conditions index; $\mathrm{BCI}$ ) or those experienced in the year of successful reproduction 5 (BY).

\begin{tabular}{lll}
\hline Response & $\begin{array}{l}\text { Fixed effects } \\
\text { (continuous covariates) }\end{array}$ & Random effects \\
\hline AFSR & HY May NAO & Year at first successful reproduction \\
& $\begin{array}{l}\text { BCI } \\
\text { BY December NAO }\end{array}$ \\
& BY May NAO & \\
SFSB & HY May NAO & Year at first successful reproduction \\
& BCI & \\
& BY December NAO & \\
& BY May NAO & \\
& CBCI & Cohort \\
PSBC & BY December NAO & Year \\
& BY May NAO & \\
& Cohort $n$ & \\
\hline
\end{tabular}

6 


\section{Table 2 (on next page)}

Top model set $(\triangle \mathrm{AICC}<6)$ explaining variation in age at first successful reproduction.

Top model set $(\triangle \mathrm{AICC}<6)$ explaining variation in age at first successful reproduction across cohorts 1983-2003 among Greenland white-fronted geese. After the nesting rule was applied ( Richards, 2008[i]), we retained four models (indicated by a '[check mark from Word here]'). 
1 Table 2. Top model set $(\triangle \mathrm{AICc}<6)$ explaining variation in age at first successful reproduction across cohorts 1983-2003 among

2 Greenland white-fronted geese. After the nesting rule was applied (Richards, 2008), we retained four models (indicated by a ' $\checkmark$ ').

\begin{tabular}{|c|c|c|c|c|c|c|c|c|c|c|c|c|c|}
\hline & $\mathrm{BCI}^{1}$ & $\begin{array}{l}\text { BY D } \\
\text { NAO }^{2} \\
\end{array}$ & $\begin{array}{l}\mathrm{HY} \text { M } \\
\mathrm{NAO}^{3}\end{array}$ & $\begin{array}{l}\text { BY M } \\
\text { NAO }^{4} \\
\end{array}$ & $\begin{array}{l}\text { BCI* } \\
\text { HY M } \\
\text { NAO }\end{array}$ & $\begin{array}{l}\text { BCI*BY } \\
\text { M NAO }\end{array}$ & $\begin{array}{l}\text { HY M } \\
\text { NAO* } \\
\text { BY M } \\
\text { NAO }\end{array}$ & $d f$ & $\log \mathrm{Lik}$ & $\mathrm{AICc}$ & $\Delta \mathrm{AICc}<6$ & $\mathrm{R}^{5}$ & Nagelkerke \\
\hline $\mathrm{m} 1$ & + & & + & + & & + & & 5 & -159.01 & 328.90 & 0.00 & $\checkmark$ & 0.25 \\
\hline $\mathrm{m} 2$ & + & & & + & & + & & 4 & -160.77 & 330.12 & 1.22 & $\checkmark$ & 0.22 \\
\hline $\mathrm{m} 3$ & + & & + & & & & & 3 & -161.97 & 330.28 & 1.39 & $\checkmark$ & 0.19 \\
\hline $\mathrm{m} 4$ & + & & + & + & + & + & & 6 & -158.64 & 330.54 & 1.64 & & \\
\hline $\mathrm{m} 5$ & + & & + & + & & + & + & 6 & -158.67 & 330.60 & 1.70 & & \\
\hline $\mathrm{m} 6$ & + & + & + & + & & + & & 6 & -158.83 & 330.92 & 2.02 & & \\
\hline $\mathrm{m} 7$ & + & & & & & & & 2 & -163.79 & 331.75 & 2.85 & $\checkmark$ & 0.15 \\
\hline $\mathrm{m} 8$ & + & & + & & + & & & 4 & -161.67 & 331.91 & 3.01 & & \\
\hline m9 & + & & + & + & + & + & + & 7 & -158.29 & 332.28 & 3.38 & & \\
\hline $\mathrm{m} 10$ & + & & + & & + & & + & 5 & -160.76 & 332.41 & 3.51 & & \\
\hline $\mathrm{m} 11$ & + & & + & + & & & & 4 & -161.92 & 332.41 & 3.52 & & \\
\hline $\mathrm{m} 12$ & + & + & + & & & & & 4 & -161.97 & 332.52 & 3.62 & & \\
\hline $\mathrm{m} 13$ & + & + & + & + & & + & + & 7 & -158.49 & 332.68 & 3.78 & & \\
\hline $\mathrm{m} 14$ & + & + & + & + & + & + & & 7 & -158.50 & 332.69 & 3.79 & & \\
\hline $\mathrm{m} 15$ & + & + & & & & & & 3 & -163.66 & 333.66 & 4.77 & & \\
\hline $\mathrm{m} 16$ & + & & & + & & & & 3 & -163.68 & 333.70 & 4.80 & & \\
\hline $\mathrm{m} 17$ & + & & + & + & + & & & 5 & -161.61 & 334.11 & 5.21 & & \\
\hline $\mathrm{m} 18$ & + & + & + & & + & & & 5 & -161.66 & 334.21 & 5.31 & & \\
\hline $\mathrm{m} 19$ & + & & + & + & & & + & 5 & -161.72 & 334.32 & 5.43 & & \\
\hline $\mathrm{m} 20$ & + & + & + & + & + & + & + & 8 & -158.14 & 334.50 & 5.61 & & \\
\hline $\mathrm{m} 21$ & + & + & + & + & & & & 5 & -161.92 & 334.72 & 5.82 & & \\
\hline
\end{tabular}




\section{Table 3(on next page)}

Model-averaged estimate, 95\% confidence intervals $(\mathrm{Cl})$ and relative importance for fixed effects in the top model set explaining variation in age at first successful reproduction.

Model-averaged estimate, 95\% confidence intervals $(\mathrm{Cl})$ and relative importance for fixed effects in the top model set explaining variation in age at first successful reproduction in Greenland white-fronted goose cohorts 1983-2003. 
1 Table 3. Model-averaged estimate, $95 \%$ confidence intervals (CI) and relative importance for fixed effects in the top model set

2 explaining variation in age at first successful reproduction in Greenland white-fronted goose cohorts 1983-2003.

\begin{tabular}{lccc}
\hline \multicolumn{1}{c}{ Fixed effects } & Estimate & $95 \%$ CI & Relative importance \\
\hline (Intercept) & 0.00 & 0.00 & - \\
BCI $^{1}$ & -0.19 & $-0.29,-0.08$ & 3.49 \\
HY M NAO $^{2}$ & -0.07 & $-0.20,0.01$ & 1.22 \\
BCI*BY M NAO $^{*}$ BCI HY M NAO $^{*}$ & -0.09 & $-0.24,-0.03$ & 1.16 \\
HY M NAO*B M NAO $^{*}$ & -0.01 & $-0.15,0.06$ & 0.32 \\
BY D NAO $^{3}$ & 0.01 & $-0.06,0.15$ & 0.26 \\
BY M NAO $^{4}$ & 0.004 & $-0.09,0.12$ & 0.14 \\
\hline
\end{tabular}

$3 \quad{ }^{1}$ Breeding conditions index (BCI)

$4{ }^{2}$ Hatch year (HY) May NAO

5 December NAO prior to successful reproduction

$6 \quad{ }^{4}$ Breeding year (BY) May NAO 